\title{
The evolution of electricity price on the German day-ahead market before and after the energy switch
}

\author{
Abdolrahman Khoshrou a, c, *, 1 , André B. Dorsman ${ }^{\text {b, } 2}$, Eric J. Pauwels ${ }^{\text {a, } 3}$ \\ ${ }^{a}$ Centrum Wiskunde \& Informatica, Science Park 123, 1098 XG, Amsterdam, the Netherlands \\ ${ }^{\mathrm{b}}$ VU University Amsterdam, 1081 HV, Amsterdam, the Netherlands \\ ${ }^{\mathrm{c}}$ Department of Mathematics and Computer Science, Delft University of Technology, the Netherlands
}

\section{A R T I C L E I N F O}

Article history:

Received 16 April 2018

Received in revised form 3 October 2018

Accepted 28 October 2018

Available online 5 November 2018

\section{Keywords:}

electricity network

Day-ahead price

Renewable energy

Volatility

Energy switch

Singular value decomposition

\begin{abstract}
A B S T R A C T
Germany is a forerunner in developing renewable energies. It is therefore of considerable interest to investigate the impact of switch to renewables on the market during transition era. The aim of this study is in two parts: 1) Investigating the volatility; and 2) Conducting a descriptive study on the evolution of daily profiles and emergence of non-positive prices. In terms of volatility quantification, the following characteristics of EPEX prices should be recognized: 1) Covering the whole year (24/7); 2) Taking nonpositive values; 3) Depending on calendar information; and 4) Changing according to demand and supply availability. We, therefore, propose a robust and generic approach to account for diurnal or seasonal patterns of human activities in volatility analysis. An important distinction of our work is in introducing an alternative representation (as matrices) for quasi-periodic price data. We, herein, propose a new notion of volatility using a matrix decomposition technique, namely the singular value decomposition (SVD). Our observations indicate price volatility reduction, in the recent years. The second part of this article provides evidences of effect of renewables on daily price profiles - emergence of nonpositive prices and also shifts of peak price values to hours where solar is less available.
\end{abstract}

(c) 2018 Elsevier Ltd. All rights reserved.

\section{Introduction}

In Europe, Germany is taking the lead in switch from fossil and nuclear to renewable energy sources (RES). This creates new challenges as wind and solar energy are fundamentally intermittent, weather-dependent and unpredictable. This energy transition or as is called Energiewende, is a prominent example of an ambitious project spearheaded by the German government intended to replace the conventional energy sources by RES, to large extent, in the coming years [1]. To secure an economic and environmentally compatible supply, Germany has substantially expanded its REScapacity, in particular wind and solar [2]. This creates new

\footnotetext{
* Corresponding author. Centrum Wiskunde \& Informatica, Science Park 123, 1098 XG, Amsterdam, the Netherlands.

E-mail address: a.khoshrou@cwi.nl (A. Khoshrou).

1 Abdolrahman Khoshrou is with the Intelligent and Autonomous Systems Group at Centrum Wiskunde \& Informatica; he is also a guest PhD student at TU Delft.

${ }^{2}$ André B. Dorsman is an associate professor at the School of Business and Economics, VU University Amsterdam.

${ }^{3}$ Eric Pauwels is a senior researcher and the leader of the Intelligent and Autonomous Systems Group at Centrum Wiskunde \& Informatica.
}

challenges as wind and solar energy are fundamentally intermittent, weather-dependent and unpredictable; it hence raises concerns over managing the flexibility in power demand and supply. It is therefore of considerable interest to investigate what effect Energiewende could have on the overall trend and volatility of the electricity price. This impact could be complex because there are two contradicting forces at play. The marginal cost of RES is relatively low and even negative (especially if subsidized), therefore, increased penetration of wind and solar would result in a downward trend in electricity prices. On the contrary, the associated uncertainty regarding the availability of wind and solar energy is expected to cause spikes in the market. In other words, the integration of RES provokes assertion that the stability of power grid can (surely) be compromised due to inherent intermittency of such sources. Therefore, the increased price volatility will cause additional market risks for suppliers and consumers on the market. While market coupling promises to reduce price volatility, dependence on RES might have the opposite effect. Because of the integration of the European grids, the problems will not be confined only to the German grid. Power quality issues and reduction of stability in Germany also means a higher instability in the neighboring grids. For example, the pros and cons of the Energiewende 
for Norwegian grid is studied in Ref. [3]. Some researchers, however, detract the latter, arguing that such assertions are irrelevant because intermittent energy sources, like wind, can and do contribute as a firm power source to the grid. Swift-Hook [4] contends that all the concerns regarding the availability of "intermittent" energy sources are already well taken care of by back-up capacities that are in place for all plants, not just for wind and solar. Another evidence in rejecting such assertions is presented in Ref. [5]; it is argued that a fully-integrated power system which includes a component of intermittent renewable generation is reliable, at least as far as providing firm supply is concerned.

Along with increase in utilization of intermittent renewable sources, short-term electricity market studies (including dayahead, intraday and imbalance market) are becoming increasingly popular. The aim of this study is in two folds. First, to investigate the volatility of the market in transition era, and second, to explore the possible effect of RES on the overall price profiles (e.g., shifts in peak price hours, emergence of zero or negative prices). In the present work, we opt to focus on the day-ahead market as it represents an important and growing segment where market mechanisms are clearly visible. Inspired by the work in Ref. [6], we herein consider matrices as an alternative representation of the electricity market data where the time series demonstrates periodic patterns. We accordingly define a new, yet easy-to-quantify, notion of volatility using a popular and numerically stable matrix decomposition technique, namely the singular value decomposition (SVD). It enables us to disentangle the matrix of daily price profiles (one year worth of hourly values) based on the most dominant daily profiles (left singular vectors as a notion of trend) and their corresponding variability (the right singular vectors), as it is fully explained in Section 3.

The rest of this paper is organized as follows. Section 2 provides a brief about the German day-ahead market, along with the data description. The next consecutive sections are dedicated to our methodologies. Section 3 introduces the singular value decomposition, as the core means of the proposed methodology in this paper. The evolution of the volatility of the day-ahead price time series is investigated in Section 4. Section 5 provides an overview of the trend changes in the German day-ahead market, in the recent years. Section 6 discusses our findings with respect to a number of similar studies. We conclude this work in Section 7.

\section{EPEX day-ahead market}

To guarantee a single integrated and transparent market, the European Power Exchange (EPEX SPOT SE) acts as a neutral intermediary market operating service provider between the market members active in the central western European countries - viz. Switzerland, France, Germany and Austria. This market consist of non-final consumers and big players in the energy sector such as utilities, wind and solar farm owners, hydroelectric power stations, aggregators, the transmission system operators (TSOs), financial service providers and also energy trading entities that are working within the energy sector on a daily basis [7].

An exchange for short-term (one day before the power delivery) electricity contracts is the day-ahead market. It is a single integrated market where the participants themselves propel the trading. An electricity buyer, typically a utility or TSO, determines how much energy it will need to fulfill its customers requirements for the coming day. It also decides how much its purchase price on hourly basis is going to be. The seller, e.g., the owner of a wind farm or hydroelectric power plant, also submits the quantity which they are prepared to deliver the next day, and the price level for each hour. The deadline for the market participants to submit the price $(€ / \mathrm{MWh})$ and the quantity (MWh) for which they seek to make a deal is 12 h00 CET (MWh stands for megawatt-hour). These "bids" are then fed into a complex algorithm to calculate the clearing price. This process, typically, takes no more than $42 \mathrm{~min}$ to clear the market and determine whether orders are accepted or rejected. In the end, the financial and physical transactions are being settled. The output of the algorithm is in fact a number of time series of prices (bounded between $[-500,3000]$ ), and traded volumes which are going to be exchanged, per area and period of the day, for the next day $[8,9]$. The delivery of power begins by the sellers at the contract rate, from 00 h00 CET the next day.

As previously mentioned, in the course of Energiewende, besides technical challenges, energy market is also undergoing paramount changes. The state-aided priority of RES generation has led to a significant decline in electricity prices.

Moreover, a bi-product of that is a reduction in the profit margin of co-generation units, and hence an increase in the necessity of flexible operations to avoid injection of power to the grid when spot prices drop below marginal costs [10]. Fig. 1 provides an overview of the evolution of the price values on the German dayahead market from 2006 until 2016 (data source: [7]). It is plain to see that after triggering the energy transition in 2011, occurrences of zero or negative price values is more frequent. Furthermore, a cursory glance at this timeseries suggests an overall downward trend in price range as well as its volatility. Table 1 contains some statistics for the same data. Interestingly enough, despite a consistent reduction in the annual mean $(\mu)$ and the standard deviation (std), the coefficient of variation $\left(C_{v}=\frac{s t d}{\mu} \times 100\right)$ has increased from 2015 afterwards.

In terms of analyzing day-ahead market, the following
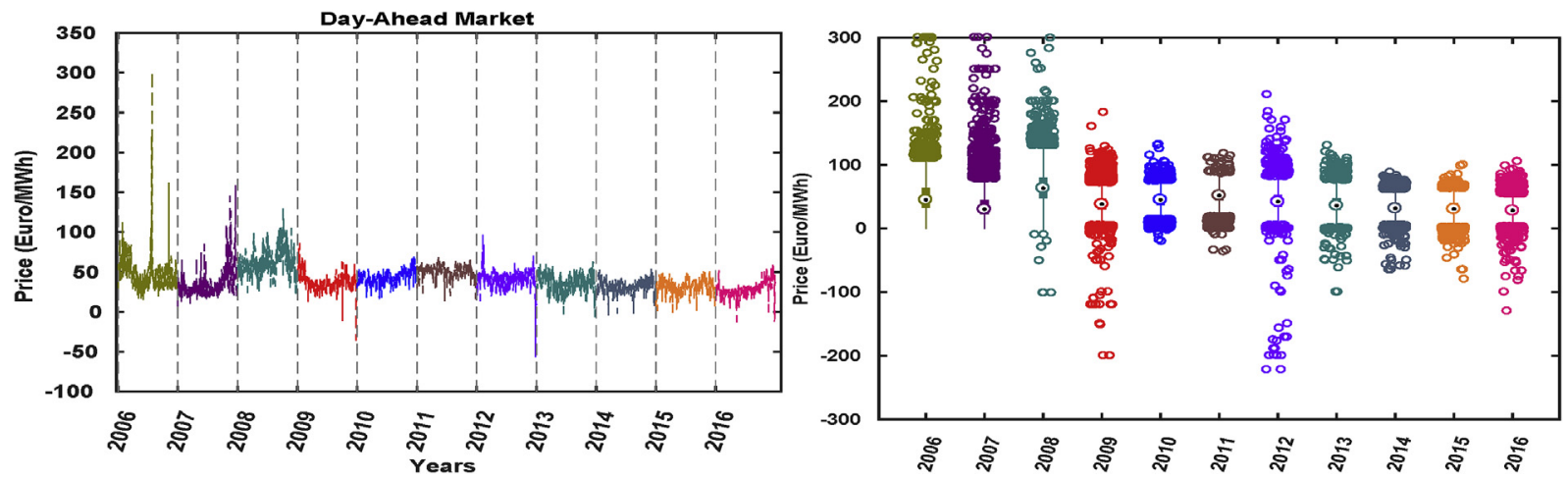

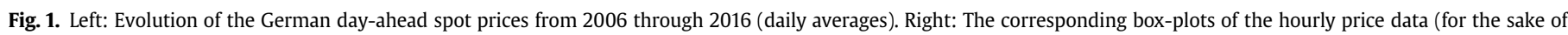
visualization, only values between $[-300,300]$ are illustrated). It is evident to see that zero or negative prices started to appear in late 2008 afterwards. 
Table 1

Annual mean, standard deviation and the coefficient of variation $C_{v}$ of EPEX price data, in the recent years.

\begin{tabular}{|c|c|c|c|c|c|c|c|c|c|c|c|}
\hline Year & 2006 & 2007 & 2008 & 2009 & 2010 & 2011 & 2012 & 2013 & 2014 & 2015 & 2016 \\
\hline$\mu$ & 50.79 & 37.98 & 65.76 & 38.85 & 44.48 & 51.12 & 42.59 & 37.78 & 32.76 & 31.63 & 28.98 \\
\hline std & 49.42 & 30.35 & 28.65 & 19.40 & 13.98 & 13.60 & 18.69 & 16.45 & 12.77 & 12.67 & 12.48 \\
\hline$C_{v}$ & 97.31 & 79.91 & 43.58 & 49.94 & 31.42 & 26.60 & 43.87 & 43.53 & 38.99 & 40.05 & 43.08 \\
\hline
\end{tabular}

characteristics need to be considered:

- EPEX prices cover the whole year, $24 \mathrm{~h}$ of the 7 days of the week Accordingly, the underlying variability of the data could wrongly be conceived as volatility whereas it in fact simply reflects the diurnal patterns of human activities. In this work, we use SVD to account for such diurnal and seasonal patterns (Section 3).

- More importantly, EPEX prices can be zero or even negative; therefore, the standard approach to switch to logarithmic measures can be done only after shifting up all values above zero by a certain threshold. On the other hand, price volatility has a dependence on the price level, which is even more pronounced when the spot prices are low [11] (also Table 1). Therefore, the generalizability of conventional approaches can be questioned, as the volatility measures can vary drastically, with respect to the magnitude of the aforementioned thresholds.

Fig. 2 provides a comparison of annual standard deviation of the logarithmic returns of the EPEX data. First, we shift up all the hourly price values $P=\left\{p_{1}, p_{2}, \ldots, p_{8760}\right\}$ ( $p_{8784}$ for a leap year) by a positive $\alpha$ value $\left(x_{t}=p_{t}+\alpha\right)$. We have considered three different cases: 1$)$ $\alpha=|\min (P)|+1$; 2) $\alpha=|\max (P)|+1$; and 3) $\alpha=501$ (Recall that $\left.p_{t} \in[-500,3000]\right)$. The logarithmic returns are then calculated as follow:

$\beta_{t}=\log \left(x_{t}\right)-\log \left(x_{t-1}\right)$

In the end, the standard deviation of the logarithmic return $\left(\beta_{t}\right)$ values are considered as a notion of annual volatility. It is plain to see that different $\alpha$ values can lead to contradictory results.

The flowchart presented in Fig. 3 displays our proposed methodology. Our database contains hourly data 24/7; we compare the yearly datasets during our observed period, 2006-2016.

In Section 3, we describe the SVD-method; further analysis of the volatility takes place in Section 4 , followed by price analysis in

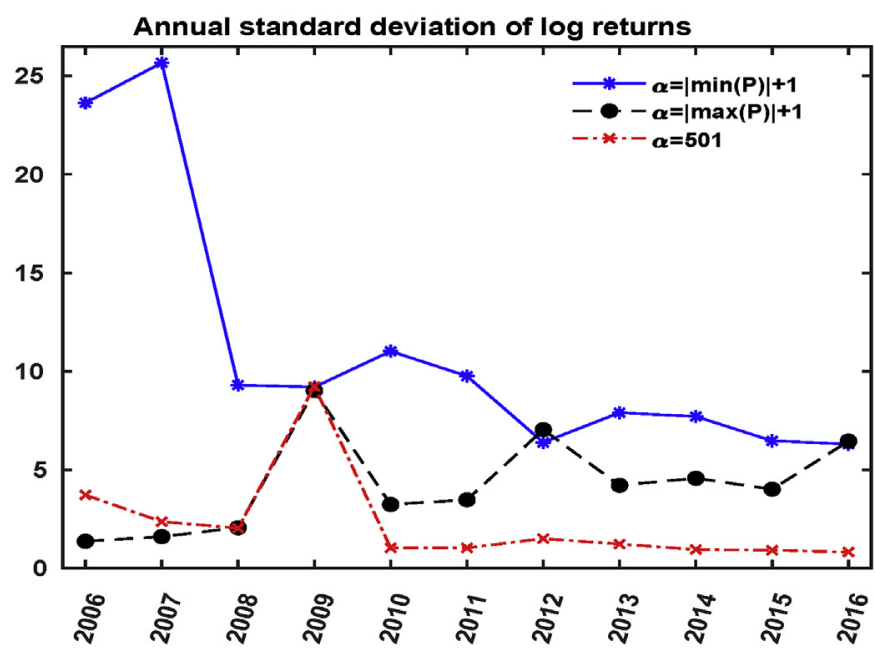

Fig. 2. Comparison of annual standard deviation of logarithmic returns of EPEX data for different $\alpha$ values.

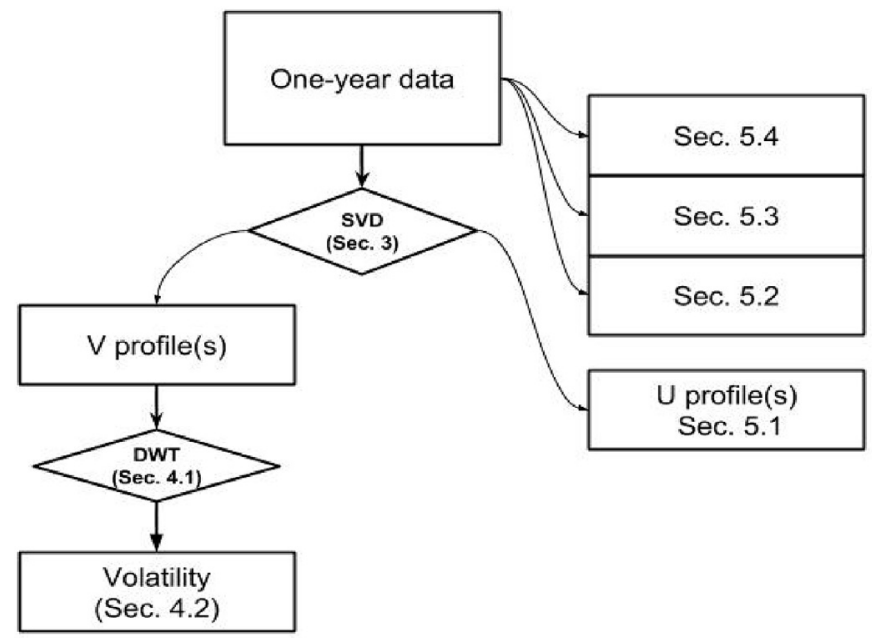

Fig. 3. Illustration of the methodology proposed in this work.

terms of trend changes in Section 5.

\section{Matrix decomposition using SVD}

The present work, considers matrices as an alternative representation for quasi-periodic time series price data. In other words, for each year, we reshape the time series data into matrix $A_{h \times d}$, where $h=24$ is the number of hours of the day, and $d=365$ (366 for a leap year) is the number of days of the year. Singular value decomposition (SVD) method is then used to decompose any given matrix $A$ into a set of fundamental daily profiles and their corresponding weights during the observed time-span (it becomes apparent in the following section). This method is more robust, regarding the aforementioned issues with EPEX price data, as it enables us to explore trend and volatility of each year individually and in a data-driven manner, with no need to add offset values. Fig. 4 displays an overview of the German day-ahead market in

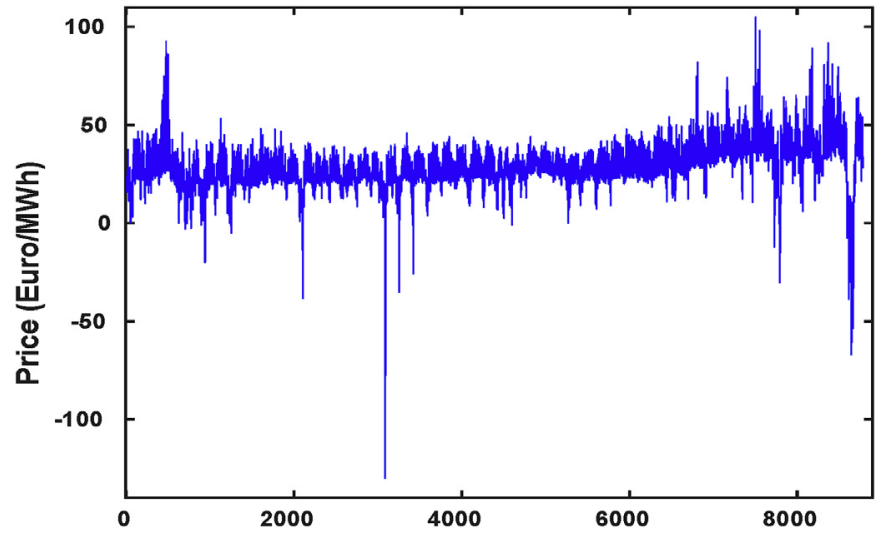

Fig. 4. An overview of the evolution of the hourly day-ahead price values in 2016 
2016; looking closely at the data, some diurnal patterns superimposed on relatively slower seasonal variations are visible. As mentioned earlier, as a first step, we recast each year's worth of data into a matrix $A_{h \times d}$ where each column contains 24 hourly values for a particular day - it can be seen as $d$ points in $h$-dimensional space.

In matrix $A$, if the daily price profiles for all $d$ days were identical (or linearly dependent), the rank of the resulting matrix will be equal to one $(\operatorname{rank}(A)=1)$, as all the columns would be the same (or linearly dependent). Put differently, the matrix $A_{h \times d}$ can be factorized as the product of a $h \times 1$ column (a typical daily profile) and a $1 \times d$ row vector, containing their corresponding weights for each day. However, in practice, the daily price profiles for subsequent days tend to differ, depending on the calendar information, supply availability and demand; accordingly, the rank of the matrix $A$ exceeds one.

In mathematical parlance, any given matrix $A_{h \times d}$ can be factorized into the product of three matrices:

$A=\sum_{k=1}^{r} \sigma_{k} U_{k} V_{k}^{T} \quad$ or more succinctly $\quad A=U S V^{T}$

where $r=\min (h, d)$, and the columns of matrices $U \in \mathscr{O}(h)$ and $V \in$ $\mathscr{O}(d)$ are orthonormal, called the left and right singular vectors, respectively. More precisely, $U_{k}$ and $V_{k}$ correspondingly denote the $k^{\text {th }}$ column of $U$ and $V$ matrices. Here, $S$ is an $h \times d$ diagonal matrix of singular values, for which only strictly positive real entries $\sigma_{k}$ are situated on the main diagonal in a descending order $\left(\sigma_{1} \geq \sigma_{2} \geq \ldots \geq \sigma_{r}\right)$. The mathematical interpretation of $(2)$ is that any given matrix $A$ can be decomposed into the sum of $r$ rank-1 matrices (i.e. a column times a row) where each next contribution in the sum is less important, based on the magnitude of their corresponding singular value $\sigma_{k}$. Another important property of the
SVD is that truncating the expansion in the right hand side of (2) after $p \leq r$ terms yields the best approximation of the original matrix $A$ by a matrix of (lower) rank - $p$; for the proof of formula see e.g., [12].

$A_{p}=\arg \min _{\operatorname{rank}(R)=p}\|A-R\|$

where the operator $\|\cdot\|$ can be either the spectral $L_{2}$ or the Frobenius norm.

Here, we exemplify the process of decomposing a matrix of the hourly price values, using the data for the year 2016 in Fig. 4. Recasting the time series data into daily segments yields a $24 \times 366$ matrix $A$ (2016 was a leap year). We then obtain its corresponding three factorization matrices using the SVD expansion. Fig. 5 illustrates the first two dominant $U_{k}$ and $V_{k}$ profiles, corresponding to the two largest singular values $\sigma_{k}(k=1,2)$.

It is plain to see that the most dominant $U$ profile ( $U_{1}$, top left), highly resembles an appropriately weighted average of daily profiles (averaged over the year). The morning and late afternoon price peaks are clearly discernible in this plot. The second column of $U$ ( $U_{2}$ bottom left) acts as a correcting factor, which needs to appropriately be added to the first profile to result in a better approximation. The panels on the right display the corresponding $V_{k}$ coefficients that specifies the magnitude of the corresponding $U_{k}$ profile for each day of the year. We, herein, propose to consider $V_{k}$ profiles as a generic notion of volatility as they appropriately reflect the variability of the corresponding $U_{k}$ profiles throughout the year. More details are presented in Section 4. Fig. 6 demonstrates the evolution of the singular values throughout the years. It is plain to see that by considering only a few singular values (and their corresponding singular vectors) we are capable of reconstructing the price data with a good approximation. In Subsection 4.2, only the
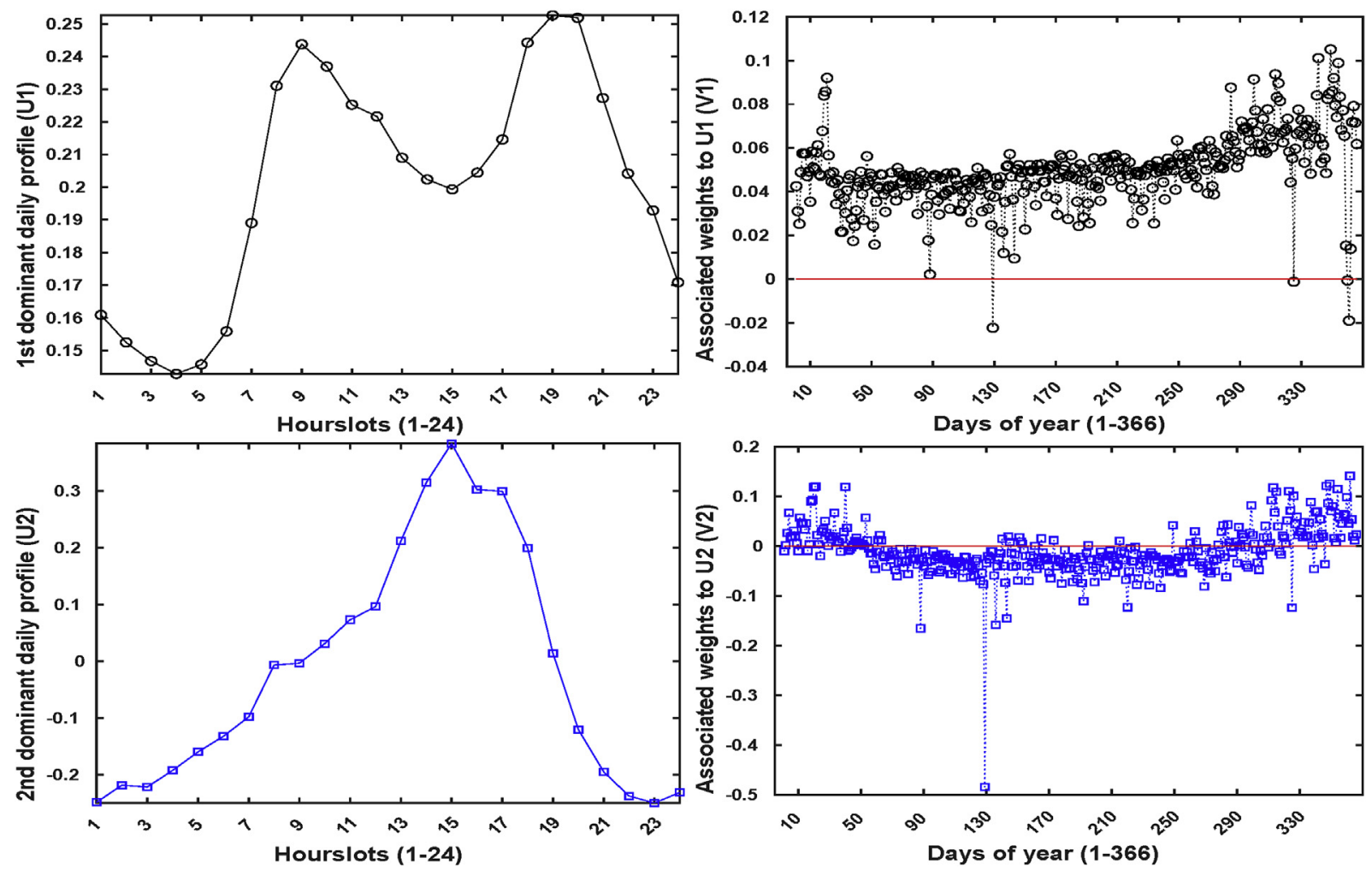

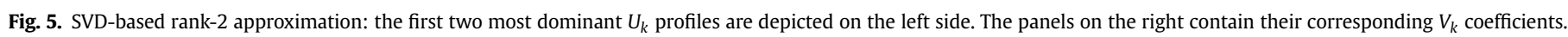




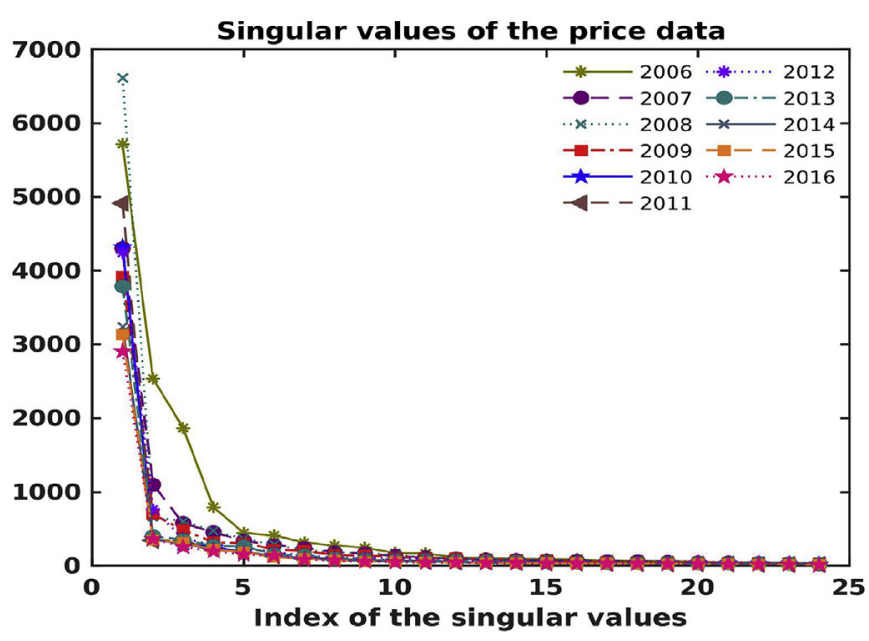

Fig. 6. An overview of the evolution of the singular value of the price data in the recent years.

first two $V_{k}$ profiles are accordingly considered to measure the volatility of data for each year.

\section{Measuring the volatility of daily profiles}

Volatility principally refers to random fluctuations of a time series about its mean or expected value. Generally speaking, in financial time series data analytics, volatility is measured by the standard deviation of the logarithmic return, or a derivation of that [13]. In the literature, numerous methods have been introduced to determine the volatility of the time series data. Diverse methods, from applied models such as Garman-Klass and Rogers-Satchell volatility estimators, to coefficient of variation based, and formal stochastic volatility models including GARCH, Heston models and so on [14]. Recently, however, new concepts and notions of volatility have been explored, especially in financial data analysis. In Ref. [15], the authors propose the permutation entropy, topological entropy and the modified permutation entropy as an alternative volatility measure. In the reported work, the degree of randomness or determinism of a time series is considered as the notion of volatility of data. Simonsen [11] studies different volatility features (including: volatility clustering, log-normal distribution, and longrange correlations) of the Nordic day ahead power spot market for the course of 12 years (1992 till May 2004). This work also reports the presence of a cyclic behavior of the time-dependent volatility for the quasi-periodic (with almost diurnal patterns) power market data. Additionally, the striking differences between the range of price data in different years is reported to be an obstacle in developing a generic approach to analyzing the market from different perspectives. The volatility has namely a dependence on price level, which is even more pronounced when spot prices are low. Therefore, as stated earlier in Section 2, in terms of analyzing EPEX data shifting up all the values for different years by a certain threshold in order to use the traditional financial data methodologies, do not appear to be a viable approach, as the results may vary drastically for different thresholds. A frequency domain based method is deployed in Ref. [16] to systematically separate out the periodic components of the prices from random variations. After removing the deterministic part, the price volatility is determined by fitting a Wiener process to the remaining random stochastic (residual) part.
With the growing contribution of RES, transmission grid extensions along with increasing cross-border interconnections capacities seem inevitable. In Ref. [17], a reduction in average price and its volatility in Ireland is concluded to be the outcome of two factors: 1) integration of wind-produced electricity into the power grid; and 2) the grid expansion between Great Britain and Ireland. On the contrary, in Ref. [18], less predictability of price values and hence increasing the allocative inefficiencies in Nordic electricity market are concluded to be an outcome of high share of windproduced energy in the grid. Schaber et al. [19] explore a number of market coupling and grid extension scenarios, using projected wind and solar data until 2020. It was done to examine the viability of such approaches in coping with the externalities associated with the growing penetration of RES in the grid. They conclude that expanding the grid is, indeed, helpful in coping with externalities which come with the deployment of renewable energies. A notable reduction in daytime peak price values in Germany and Italy is discussed to be the result of substantial expansion of the photovoltaic (PV) produced energy in these countries, according to [20]. Adaduldah et al. [21] investigate the German market after triggering the energy switch in 2011, by taking into account the priority that the German policies assigns to renewables over fossil fuels in case of adequate supply. The authors report the existence of convincing evidence for the impact of RES on the emerging of negative prices on the German day-ahead market. The wavelet decomposition technique is used herein to quantify the volatility of the EPEX price data.

\subsection{Wavelet decomposition}

In modern mathematics, wavelets are one of the most efficient and widely used tools to analyse digital signals. As the name suggests, wavelet analysis is akin to Fourier analysis which decomposes the signal of interest as a linear combination of sinewaves of different frequency and phase.

Wavelet analysis will not only tell us which frequencies are hidden in the signal, but can also pinpoint their location in the data stream. From this, it becomes clear that wavelets hand us a useful tool to probe the data for the occurrence and location of highfrequency fluctuations [22].

The Haar wavelet is arguably the simplest wavelet and lends itself to a straightforward interpretation. It basically takes any discrete signal $\mathbf{x}=\left(x_{1}, x_{2}, x_{3}, \ldots\right)$ and creates an approximation $\mathbf{a}$ and detail $\mathbf{d}$ signal by running the following simple recipe:

1. Take the first two elements $x_{1}$ and $x_{2}$ and compute the approximation and detail coefficients:

$a=\frac{x_{1}+x_{2}}{2}$ and $d=\frac{x_{1}-x_{2}}{2}$.

Notice that this implies $x_{1}=a+d$ and $x_{2}=a-d$, or more explicitly: the approximation coefficient equals the mean of the two values, and the detail coefficient the amount of deviation between the actual value and the approximation.

2. Store the results in the approximation and detail vector, respectively:

$\mathbf{a}(1)=a \quad \mathbf{d}(1)=d$.

Both vectors have a length equal to half the length of the original input $\mathbf{x}$. 
3. Move on to the next pair $\left(x_{3}, x_{4}\right)$ and continue until all $\mathbf{x}$-elements have been processed. This way we get the level-one approximation $\left(\mathbf{a}_{1}\right)$ and detail $\left(\mathbf{d}_{1}\right)$ coefficient (each vectors of half the length of the original $\mathbf{x}$-sequence).

4. To compute the level-two approximation and detail coefficients we repeat the whole procedure but use $\mathbf{a}_{1}$ as input (instead of $\mathbf{x}$ ).

5. This can be continued until we have reached a pre-defined level.

Fig. 7 exemplifies the decomposition for a (short) discrete signal $\mathbf{x}=\left(x_{1}, x_{2}, x_{3}, x_{4}\right)$. In the first analysis step, the original values (the dots) are paired, and each pair is replaced by its mean or approximation ( $a_{i}$, the dash-dotted lines) and the symmetric deviation $d_{i}$ with respect to the corresponding mean. As a consequence, the original signal $\mathbf{x}$ can equally well be represented by the approximation vector $\mathbf{a}=\left(a_{1}, a_{2}\right)$ and the vector of detail coefficients $\mathbf{d}=$ $\left(d_{1}, d_{2}\right)$. The next analysis step (not depicted here) would repeat the procedure, this time starting with the approximation a as input. As a concrete example, imagine that the time series is given by $\mathbf{x}=$ (1 $55 \quad 11 \quad 1 \ldots)$, then

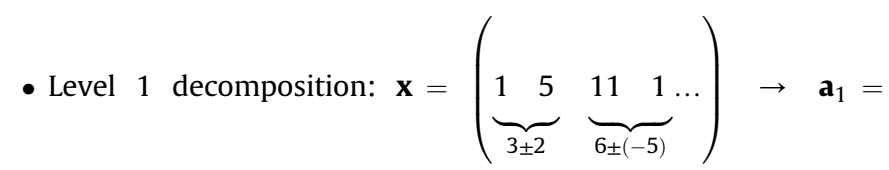
(3 6...) and $\mathbf{d}_{1}=\left(\begin{array}{ll}2 & -5 \ldots\end{array}\right)$

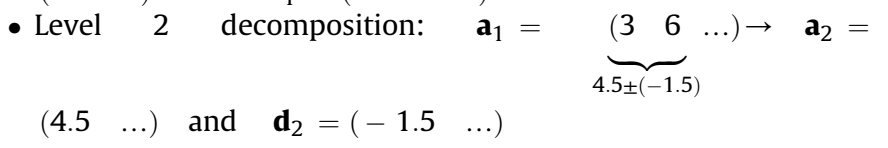

\subsection{Volatility quantification}

It is important to realize that the level-one detail coefficients capture the highest frequency oscillations. Subsequent detail coefficients correlate with oscillations of successively lower frequencies. As mentioned before, in the present work, the right singular vectors $V_{k}$ are considered to be an indicative for the volatility of the fundamental daily price profiles $\left(U_{k}\right)$ throughout a year. We hence have applied the wavelet decomposition to the absolute value of the first two $V_{k}$ profiles. Fig. 6 confirms that there are only a few dominant singular values; we hence opt to consider only the first two right singular vectors. Fig. 8 contains the standard deviation of the values of the Haar wavelet detail coefficients, down to three level wavelength decomposition. The downward trend underscores a reduction in the volatility of the German day-ahead market in the recent years. Worth noting that $V_{1}$ and $V_{2}$ coefficients have been magnified using their corresponding singular values $\sigma_{1}$

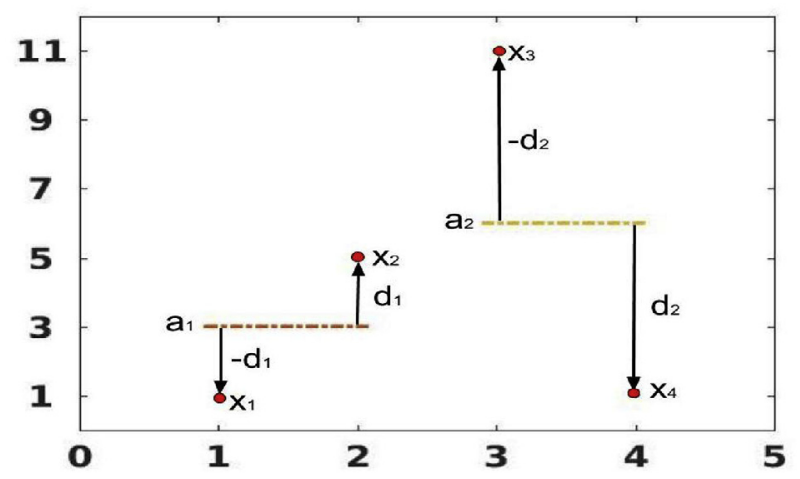

Fig. 7. Schematic representation of the Haar wavelet decomposition. and $\sigma_{2}$. The results here corroborate with [23], where the volatility of the German day-ahead market during the same period is studied.

\section{Extracting the underlying trends}

This section is dedicated to a more a descriptive study on the evolution of the overall trend of the day-ahead market.

\subsection{The evolution of the daily profiles}

As mentioned before, the left singular vectors ( $U_{k}$ profiles) represent the most dominant daily profile $\left(U_{1}\right)$ and its additive corrective profiles $\left(U_{2}, U_{3}, \ldots\right)$. Fig. 9 displays the evolution of the most dominant daily price profiles ( $U_{1}$ magnified by $\sigma_{1}$ ) over the years. A continuous downward trend during the decade in the average value of the daily profile is noticeable. More importantly, the change in the overall shape of the daily profile is even more telling. Before 2011, the morning peak price values tended to be higher than the afternoon peak values. Whereas this trend has become reversed in the recent years. Another intriguing feature of the data is the shift of the time slot (during the day) for which more points to the effect of the low cost subsidized RES on the daily price profile. Before 2011, the electricity price is most expensive at around $12 \mathrm{~h} 00$. Evidently, the availability of solar after 2011 has pushed the prices lower and has led to a morning peak prices at around 9h00. In a similar way, the afternoon peak price time slot has a shift of an hour from around 19h00-20h00. Furthermore, it is plain to see that the ranges of the daily profiles (difference between the maximum and minimum values) shows a reduction, in the recent years. This also can be an indicative of less volatility in years.

In other words, the change in timing and amplitude of daytime and evening time peak values after 2011 are striking. Before 2011, the midday peak price (around 12h00), was considerably higher than the early evening spike around 20h00. However after 2011, the first spike is not just lower than the second one, but also shows a clear shift to earlier hours. This makes sense in light of higher contribution of renewables, in particular solar; it is reasonable to assume that the typically high supply of solar power around midday is the reason for drop in prices during these hours. The right panel of Fig. 9 displays an alternative representation of the same data in the left panel; it confirms the previous findings by showing a downward trend in average daily prices from left to right. The diminishing contrast in each column indicates a smoother price profile with lower daily spread over the years. Looking closely, the shift of the midday and afternoon peak hours is notable.

\subsection{The extreme values}

In the next step, the extreme values of the hourly prices during the years has been probed. More specifically, collecting all the hour slot values for each year in the period 2006 through 2016 yields a price distribution for each year. Extreme prices (both high and low) are characterized as prices outside the extreme $5 \%$ percentiles. So we get a representative value for high (low) prices by focusing on the values of the $95 \%$ ( $5 \%$ respectively) percentile for the distribution of each year's worth of hourly price values. The results are shown in Fig. 10 where we have plotted both values (high and low) for each year. There is a pronounced continuous downward trend for the high prices, with 2008 being an obvious outlier. The lowest prices show a slight decrease over the years, as there is obviously less room for manoeuvre. The overall spread of the prices is steadily decreasing and less volatile, indicative of a more mature market. 

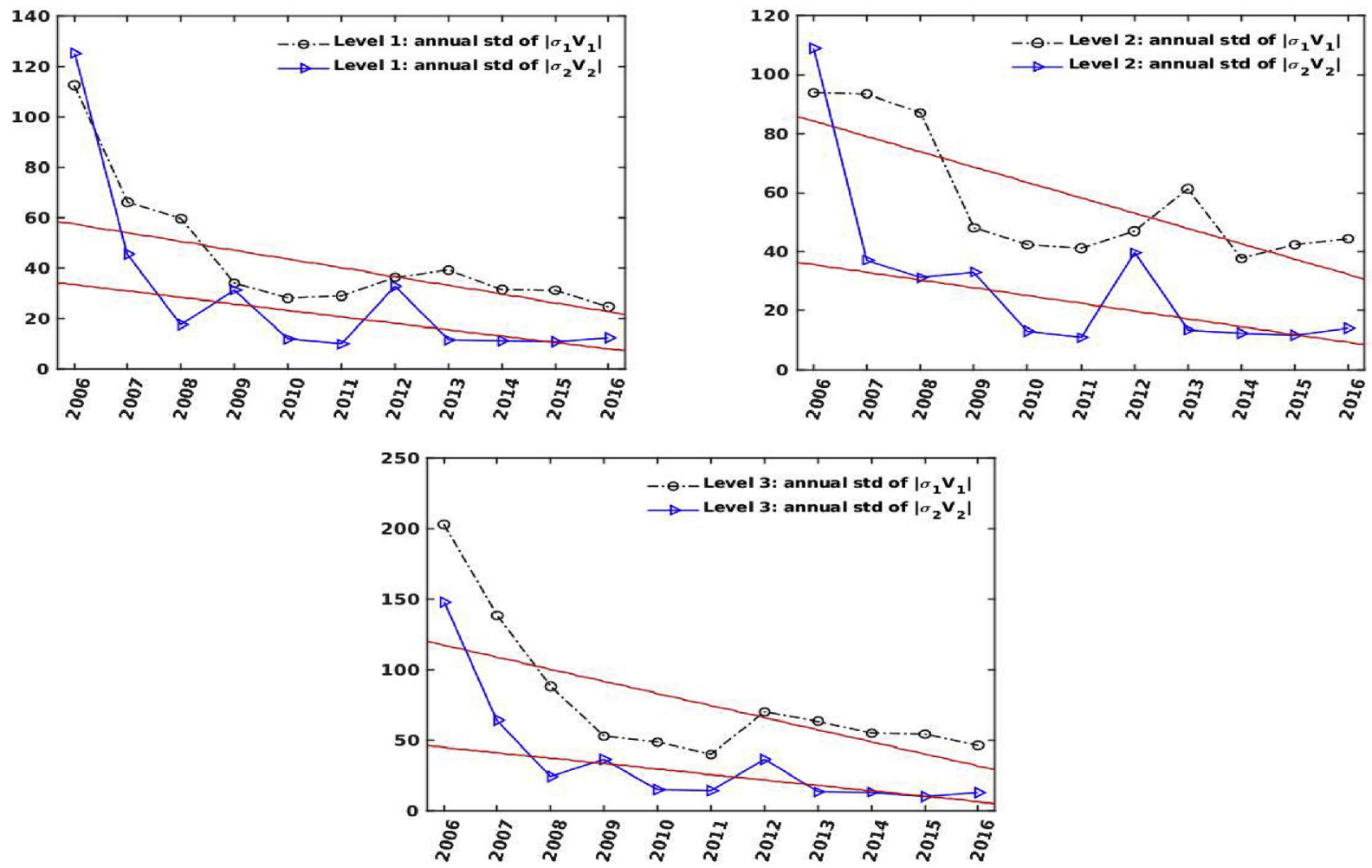

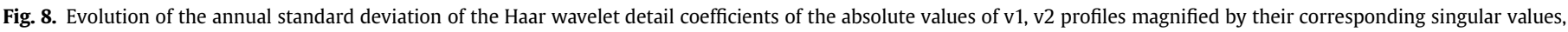
down to three level (starting from the top left).
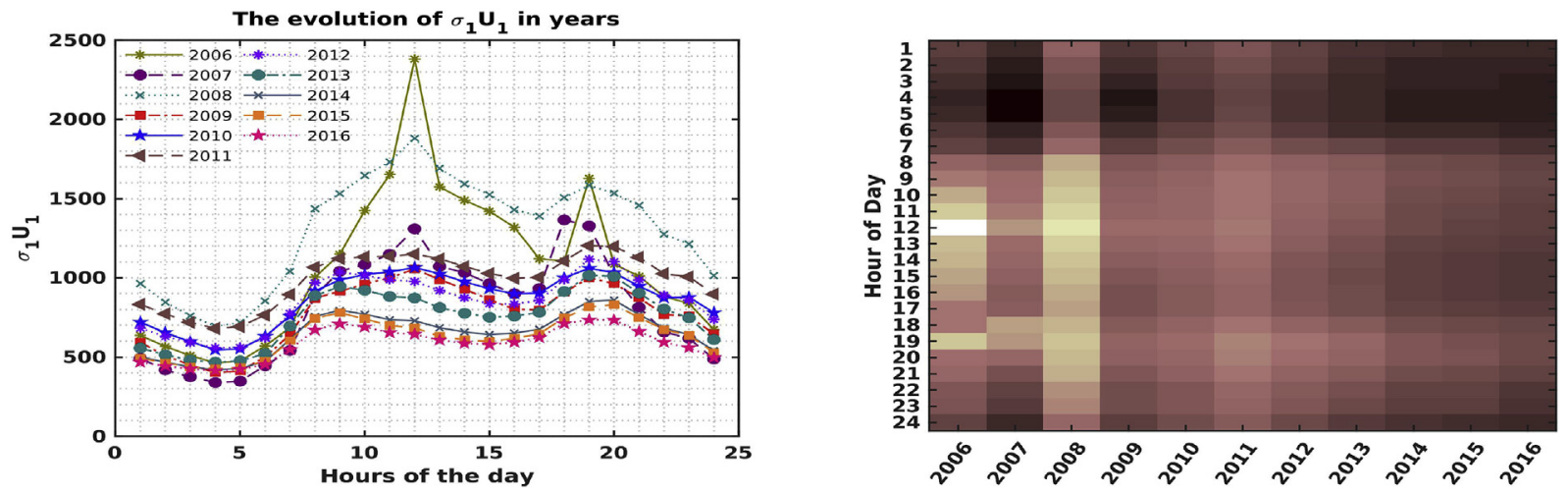

Fig. 9. Left: Averaged daily profiles of the day-head prices. Right: An alternative representation, for the sake of better visualization.

\subsection{The distribution of high and low price values}

We herein explore the evolution in the distribution of occurrences of the extreme prices over the course of the day. Recall that high (low) prices are defined as values outside the 95th (5th) percentile of price distribution for that year. Fig. 11 (left panel) shows how the occurrence of low prices is distributed over the day (for the years 2006 through 2016). Whereas in the earlier years of the decade, there is a clear concentration of low price occurrences in the early morning ( $4 \mathrm{~h} 00-5 \mathrm{~h} 00$ ), later years show a more uniform daily distribution. A similar distribution for the occurrence of high prices is shown in the right panel of Fig. 11. It indicates a distinct shift (occurring around 2011) in the time slot of high prices. More precisely, the day time peak is shifted from noon to the earlier hour of $9 \mathrm{~h} 00$, while the evening is postponed, shifting from 19h00-20h00. In other words, before 2011, the daytime peak values were higher than the afternoon ones, and occurred around noon.

After 2011, high prices occur predominantly at the beginning and end of the peak period. Each column represents 440 values, which is $5 \%$ of the total number of observations during one year. Also apparent is the fact that, starting in 2011, the afternoon spikes in the price profile exceed the daytime ones. 


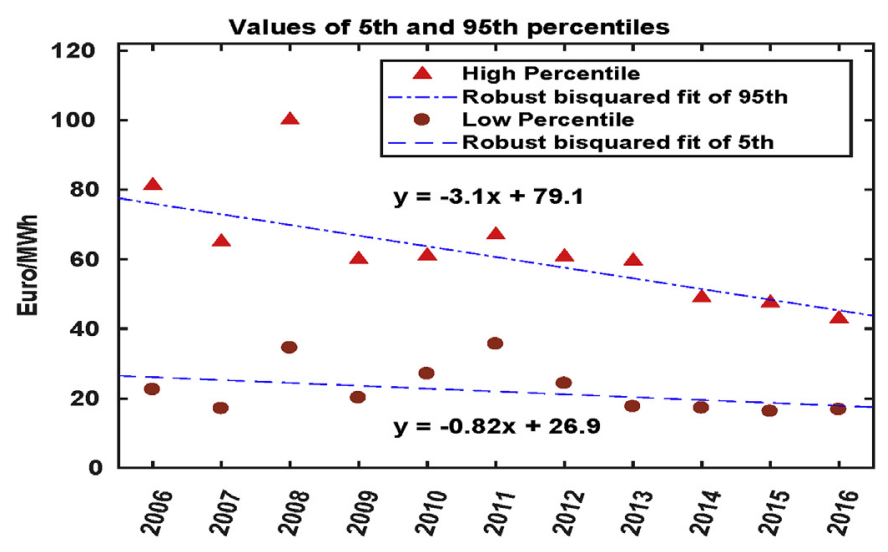

Fig. 10. The evolution of extreme prices shows a consistent downward trend in the data.

\subsection{Zero and negative prices}

Of special interest are zero or negative prices as they reflect the effect of subsidized RES. In Germany, significant amount of electricity is still produced by conventional sources. In 2015, e.g., lignite, nuclear energy and hard coal were responsible for producing 24 , 14.2 and $18.3 \%$ of gross electricity production, respectively [24]. The synchronization speed of these plants is slow and they can not be shut or ramped down very quickly.

As a result, on some days when there is excess of electricity production by subsidized renewable energy sources, prices may become negative and consumers can actually make a profit by consuming electricity. Fig. 12 provides an overview of the frequency along with the magnitude of non-positive prices, in the recent years. More specifically, the width (on the $x$-axis) of the interval assigned to each year is proportional to the number of occurrences of negative (or zero) prices in that year. The $y$-axis depicts the corresponding magnitude of these negative prices. Starting in 2012, the number of occurrences (length of the interval) seems to increase steadily. This trend is strikingly consistent with the growing contribution of wind and solar energy in Appendix A. From this graph it transpires that there is a reduction in the magnitude of the negative prices in the recent years, although their number is mildly increasing.

The distribution of the growing number of instances of zero as well as negative prices in the recent years, from a different perspective is illustrated in Fig. 13. The left panel highlights the

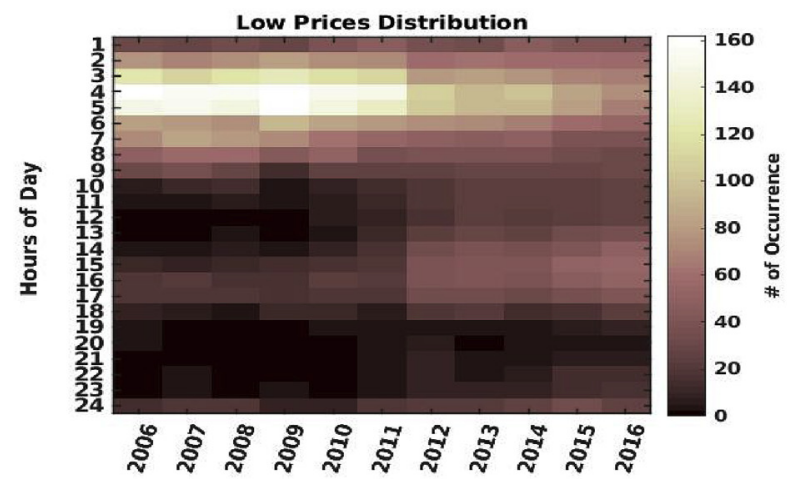

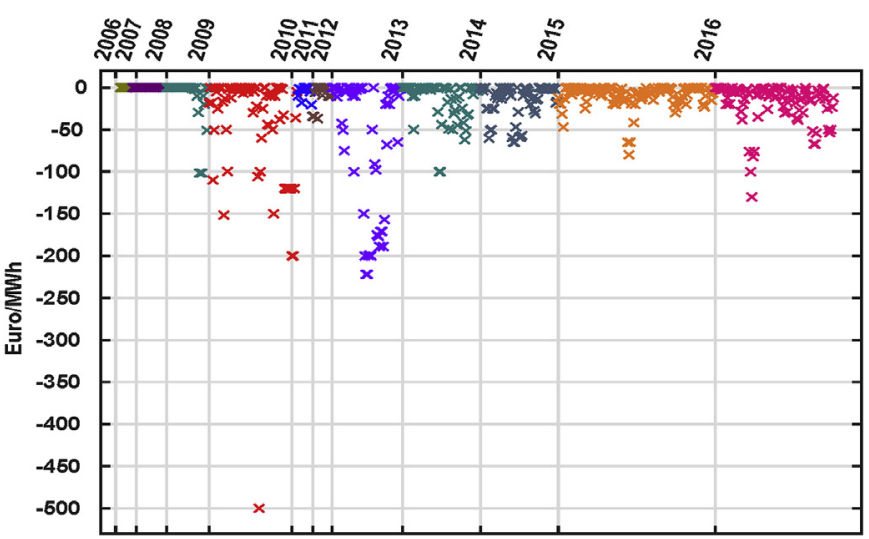

Fig. 12. An overview of the occurrences of zero or negative prices.

frequency of occurrence of non-positive price values during different hours of the day, for each year. Although, before 2012, the majority of non-positive prices are happening in early hours of the day, a cluster of non-positive price values has appeared during the midday (11h00-18h00). Considering the fact that the electricity demand during these hours has not changed much (working hours), the most probable explanation for this change can be the oversupply by solar farms. As it is seen in appendix A.2, these are the hours with the highest solar energy availability; on average, at 13h00, solar production can become as high as $5 \mathrm{GW}$-hour (GWh), that is almost 5 times more that solar feed-in at $10 \mathrm{~h} 00$. This number can be even more during the summer. Appendix A.3 highlights the fact that wind and solar energy combined are responsible for almost $10 \mathrm{GWh}$ feed-in at around $13 \mathrm{~h} 00$, throughout the year. Another conspicuous observation in the left panel of Fig. 13, is the increased frequency of the occurrences of non-positive prices in the early hours of the day in the last two years. Interestingly enough, Appendix A.1 presents how the wind feed-in have notably increased in 2015 afterwards. The right panel of Fig. 13, confirms the fact the non-positive price values are most frequent during the weekends, when the consumption is low. However, we witness more instances of zero or negative prices during the week, from 2011 afterwards.

\section{Discussion}

The following is a discussion on the findings that were presented in the previous sections.

Fig. 11. An overview of the distribution of low prices over the day (left), vs. high prices (right), throughout different years. 

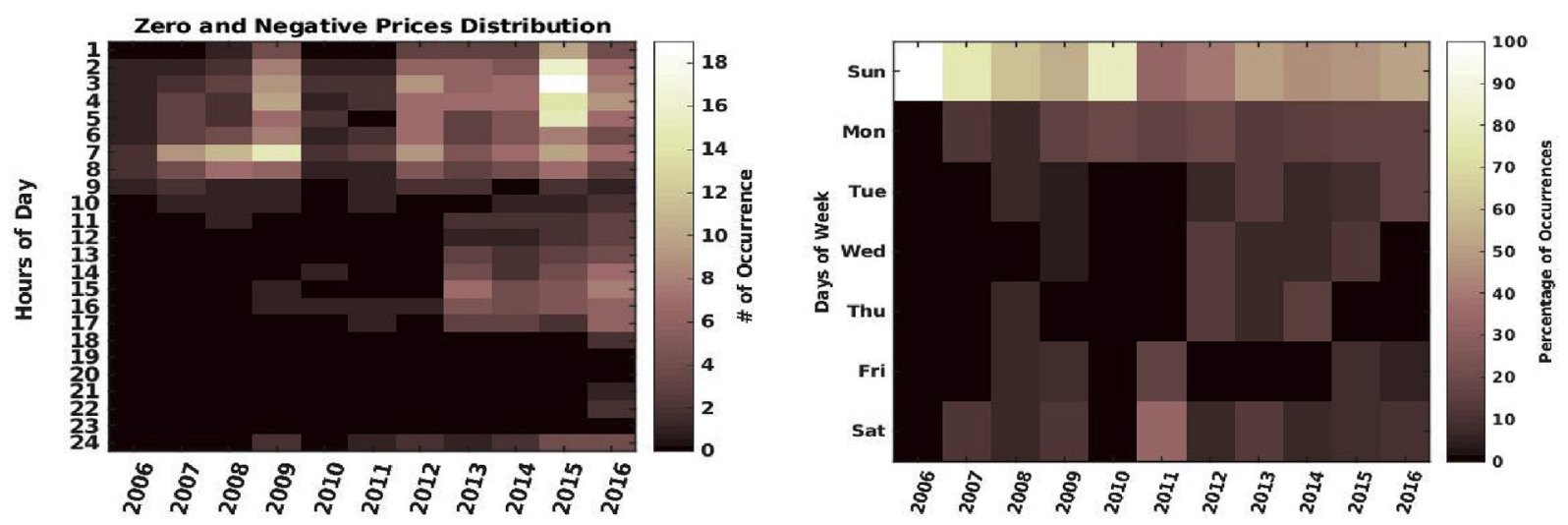

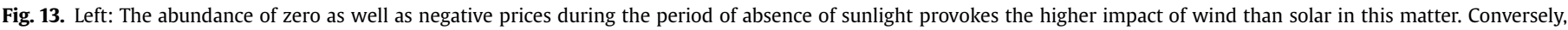

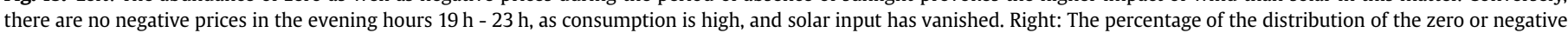
prices on the days of week.

\subsection{Volatility}

Our results suggest that the increasing integration of RES has not resulted in a more volatile day-ahead market. This implies that the counter measurements taken in Germany have been quite successful. Furthermore, our results is in line with [5] where it is argued that there are ways to tackle the issues related to the inherent variability of renewables. Possible explanations for the absence of an increase in the price volatility on the day-ahead market are that the TSOs assist each other (Subsection 6.4) or make use of the intraday market (Subsection 6.6). In this paper, we observe that in terms of the day-ahead electricity market, there is no sign of increase in the price volatility.

\subsection{Impact on electricity price}

The energy switch from fossil fuels to renewables attracted authors to research the impact of this switch on for example the electricity prices. Zipp in Ref. [25] researches the "merit-order effect" of the energy switch in Germany (and Austria) during the period 1 January 2011 to 31 December $2013 .{ }^{4}$ The merit-order is a way of ranking available sources of energy, especially electrical generation, based on ascending order of price with amount of energy that will be generated. Due to the fact that producers of renewable energy comparing to the producers of fossil fuel have large fixed and small variable costs, renewable energy will be used before fossil fuel. Zipp shows that a systematic reduction of the average day ahead price on days where more variable renewable energy, such as wind and solar energy, are available. Zipp found for each year in the period 2011-2013 a negative influence of the wind and of the solar energy on the daily average electricity price. His results are in line with earlier studies of Cludius et al. [26] and Wrzburg et al. [27]. The results of Zipp are in line with our results. However, we did not only show a negative effect of energy switch on the electricity price, but also a change of the daily pattern of this price. We show in Fig. 9 that before and after triggering the energy switch in 2011, not only the electricity price was lowered by the increasing wind and solar energy, but also the morning peak at $12 \mathrm{~h} 00$ (before 2011) has switched to 9h00, and similarly, the afternoon peak has shifted from 19h00-20h00.

\footnotetext{
${ }^{4}$ Germany and Austria share a common grid.
}

\subsection{Negative electricity prices}

Another striking issue is the emergence of non-positive price values during our observed period (2006-2016). The marginal costs of renewables is (nearly) zero. In Germany the production of wind and solar energy was subsidized, which means that even in the case of negative prices - as long as the subsidy covered the negative price - it was attractive to sell the energy and to pay for this selling possibility. Brijs et al. [28] investigate the emergence of negative prices in Belgium, France, Germany and The Netherlands for the period 1 December 2012 till 30 November 2013. They conclude that the negative imbalance prices are substantially induced by the expected generation of wind and solar during low energy demand periods. In our study, our observed period is longer, namely 2006-2016. After 2012, we observe also non-positive prices during the hours $11 \mathrm{~h} 00-17 \mathrm{~h} 00$. The cause of negative prices during peak hours is the increase in solar feed-in. Before 2012 the supply of solar energy was smaller and had apparently not much influence on the electricity price.

\subsection{Interconnectors}

The transmission system operator (TSO) is responsible balancing the demand and supply of energy for any moment. The shift from fossil fuels to renewables, however, increases the volatility at the supply side of the grid. This shift complicates the task of the TSO. TSOs can help each other in balancing the grid. Consequently, in the recent years, the number of interconnectors between countries has increased substantially. For an island like Ireland such assistance is very limited. Denny et al. [29] look into the influence of wind energy on the electricity price in 2009. In that year only one interconnector was operating, namely the interconnector called Moyle (operator: Mutual Energy), it was opened in 2002 and has a capacity of $500 \mathrm{MW}$ (MW). This capacity is nearly $5 \%$ of the installed capacity [29]. The second interconnector, East West Interconnector (EWIC), has been in commercial operation since December 2012 [30]. Greenlink is the third 500MW interconnector, linking the electricity markets in Ireland and Great Britain, is planned for commissioning in 2023 [31]. Furthermore, it is easier for a larger country to manage an additional supply of (renewable) energy. Germany is a large country and located in the center of Europe. However, Dorsman et al. [32] show that the production of renewable energy is located in the north of Germany, whereas the demand for electricity is in the south part; but the tools for transport of the electricity from north to the south of 
Germany is very limited. They also mention that the neighbors of Germany are not pleased when they receive the additional energy produced by wind and solar farms in the north. In other words, the imbalance on the German grid, due to the switch to renewables, on sunny and windy days are exported and are causing imbalances on the neighboring grids. The neighboring countries are not happy to pay the price (imbalance on their grid) for the energy switch (Energiewende) in Germany.

\subsection{Access to the grid}

Access to the electricity and gas network is not the same for every country. In Germany and The Netherlands, the access for every household is (nearly) a hundred. Recently, the Dutch government has decided to shut down a major gas production facility in Groningen (North Nederland) by 2020. The local population no longer accepts string of earthquakes caused by the extraction of gas. The gas field in the Netherlands is the largest producer in the EU. The gas is not only being used internally, it also being exported to other countries, for example Germany. Gas is among the cleanest (the smallest $\mathrm{CO} 2$ pollution) fossil fuels. Although Germany wants to switch from fossil fuel to renewables, they prefer to reduce the production of lignite, coal and oil above the reduction of gas and therefore support the North Stream 2, the second gas pipeline from Russia to Germany. In other countries the access to the grid (electricity and/or gas) is not so well distributed. Although low domestic gas prices in Russia is a huge hurdle for a switch from fossil fuel to renewables, Vasileva et al. [33] believe in line with Martitot [34] that renewables are a good alternative for remote areas. Karunnathilake et al. [35] look at the best scenarios for net-zero energy communities powered by renewable energy. They show that the optimal structure under a "pro-environment scenario", existence of small hydro, onshore wind and biomass combustion technologies, deviates from a "pro-economic scenario", where biomass combustion, small hydro, and landfill gas have the best rankings.

\subsection{Intraday trade}

An alternative for the TSO to balance between demand and supply is to use the possibilities of the intraday market. Comparing to other European countries, the intraday market is well developed in Spain. Chaves et al. [36] show that the Spanish intraday market has effectively contributed to renewable generation balancing. Also other TSOs are more often using the intraday market to balance the grid due to the increased volatility of the supply caused by the relative higher supply of solar and wind energy. However, these intraday markets are mostly bilateral and data are missing to research the growing contribution of the intraday market in solving the uncertainty issues of the TSOs.

\section{Conclusions}

The decision of the German government in 2011 to stimulate RES-generation has had a noticeable impact on the day-ahead electricity market. In this paper, we have traced such impact in two parts, in terms of volatility and overall trend changes, in the recent years. The price volatility is mostly originated by uncertainty in supply or demand. The focus of the present work is on the volatility of the daily price profiles prompted by renewable energy sources. Regarding the volatility quantification, there are a number of peculiarities that make conducting the empirical methods onerous. EPEX price data have the following characteristics: 1) It covers the whole year, $24 \mathrm{~h}$ of 7 days of the week; 2) It can have non-positive values; 3 ) It depends on the calendar information (working and non-working days); and 4) It shows daily upward and downward trends following the demand and also the supply availability. Therefore, there are a lot of underlying variability in data that simply reflects the diurnal patterns of human activities, and not reflecting the volatility. Furthermore, regarding the second point (non-positive values), the traditional approach in financial time series analysis to switch to logarithmic measures is impractical, without shifting up all the values by a certain threshold. On the other hand, the price volatility has a dependence on the price level, which is even more pronounced when the spot prices are low. Therefore, with respect to the magnitude of the aforementioned threshold, results can vary drastically. We hence have explored an alternative approach by representing the market data as matrices rather as timeseries. A novel and generic notion of volatility was accordingly defined using a well-known and numerically stable matrix decomposition technique, namely the singular value decomposition (SVD), combined with Haar wavelet transforms. The second part of this article was dedicated to a descriptive study on the trend changes of the day-ahead market. Our observations indicate a price volatility reduction and also prominent changes in the day-ahead price profiles, in the recent years. There is an overall downward trend in the average electricity price. This undoubtedly has a number of causes, but the increasing penetration of subsidized solar and wind power accounts for at least part of it. Moreover, the traditional $12 \mathrm{~h} 00$ peak before the Energiwende (Energy switch) are flattened out and shifted to earlier hours in the morning at 9 h00. In a similar manner, the afternoon peak price hours has shifted $1 \mathrm{~h}$, from $19 \mathrm{~h} 00-20 \mathrm{~h} 00$. Indeed, it is possible to clearly trace the impact of solar on the change of the daily price profile over the year (this effect is most pronounced in summer). Furthermore, the effect of the growth in wind power is most transparent in the shift in distribution of low and negative prices during the day.

\section{Acknowledgment}

The authors gratefully acknowledge partial support by the Dutch NWO-TTW under project grant Smart Energy Management and Services in Buildings and Grids (SES-BE).

The authors also would like to thank the anonymous reviewers for their fruitful comments.

\section{Appendix A. EPEX market and RES feed-in}

The following section contains some evidences of the impact of the day-ahead estimated wind and solar feed-in on the price changes (Section 5), in the recent years.

\section{Appendix A.1. Day-ahead wind energy feed-in (in GWh)}

Fig. A.14 provides an overview of the evolution of the wind feedin (day-ahead forecasts) over the years. The left panel in Fig. A.14 indicates a smooth annual growth. In a similar way, the right panel highlights the fact that the production is relatively constant around the clock. The change in the annual average of the daily profiles from 2014 afterwards is noticeable. Peak production of the wind profile is eventually moving from early afternoon to late night or early morning. This can become an issue for the stability of the grid, as there might not be enough demand during those particular hours. 

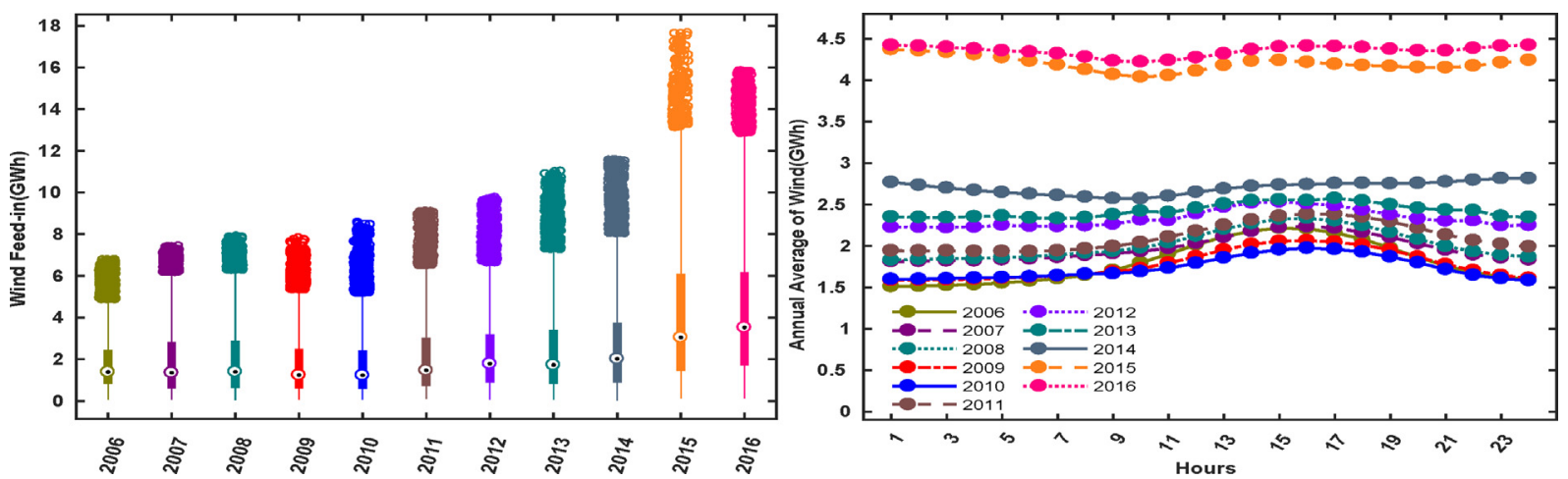

Fig. A.14. Top: The consistent growth in wind energy feed-in over the years. Bottom: Annual average of the daily profiles.
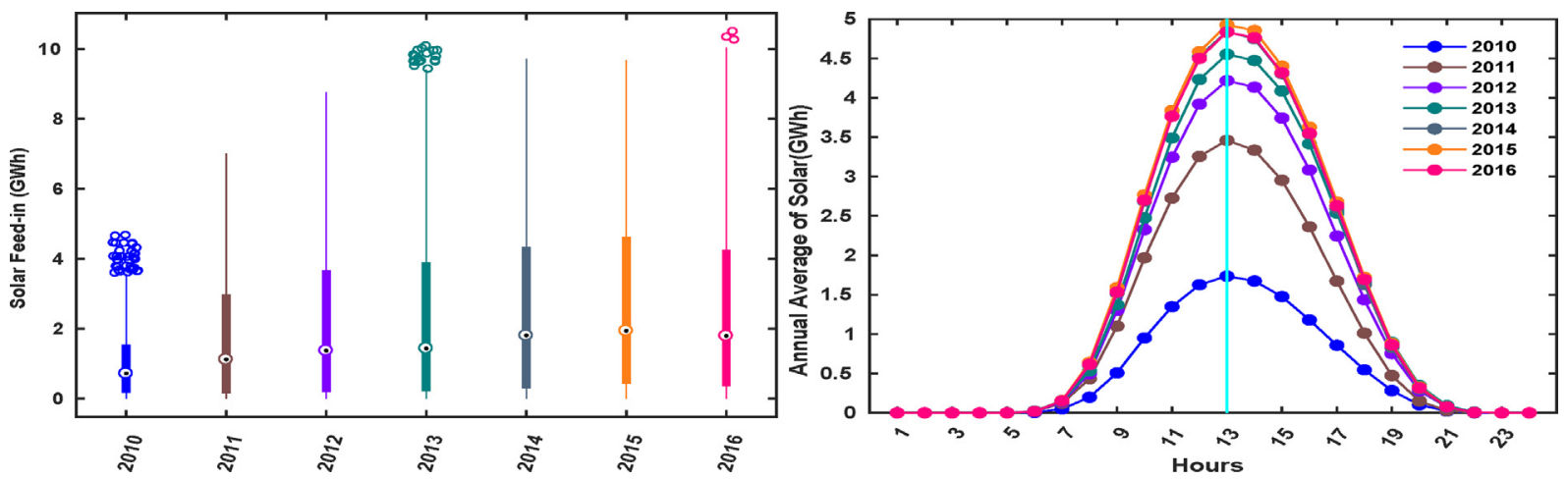

Fig. A.15. Left: Smooth growth in annual solar energy feed-in (only non-zero day-time values have been considered). Right: Annual daily average of the solar feed-in.

Appendix A.2. Day-ahead solar energy feed-in (GWh)

The developments in energy storage technologies and also the falling costs of harvesting solar power have made it increasingly attractive for the private households [37]. Fig. A.15 shows the daytime (non-zero values) solar energy feed-in forecast from 2010 to 2016. After the rapid rise in 2010 through 2013, solar feed-in has leveled off in the last two years. The panel on the right in Fig. A.15 illustrates the annual averaged solar feed-in for each time slot for years 2010-2016. Peak of solar feed-in is around 13h00; that coincides with the high demand during the day.

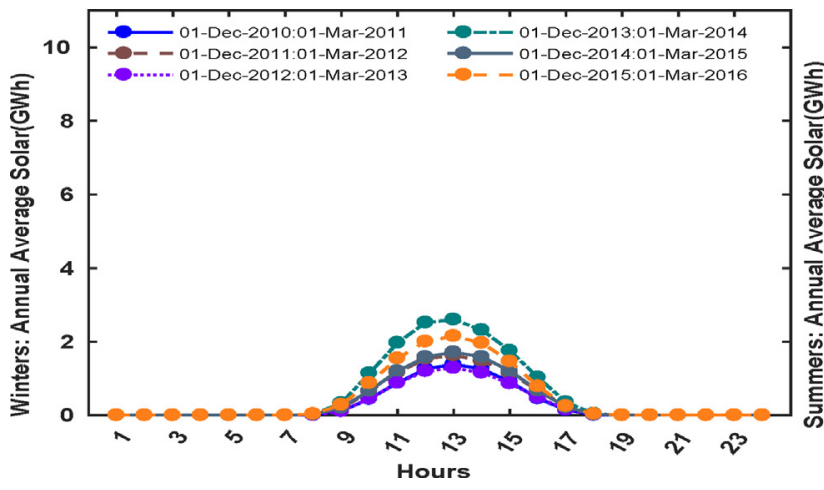

Appendix A.3. Evolution of German day-ahead price during winter and summer

To illustrate the impact of solar energy on the price, we scrutinize the data separately for the summer (June through August) and winter (December through February) periods. In winters, days are shorter and the sun, if it emerges at all, traces out a lower path in the sky; therefore, a significantly smaller amount of solar energy is produced (Fig. A.16). Wind energy, on the other hand, is fairly constant throughout the day, but there are marked difference between the seasons (Fig. A.17).

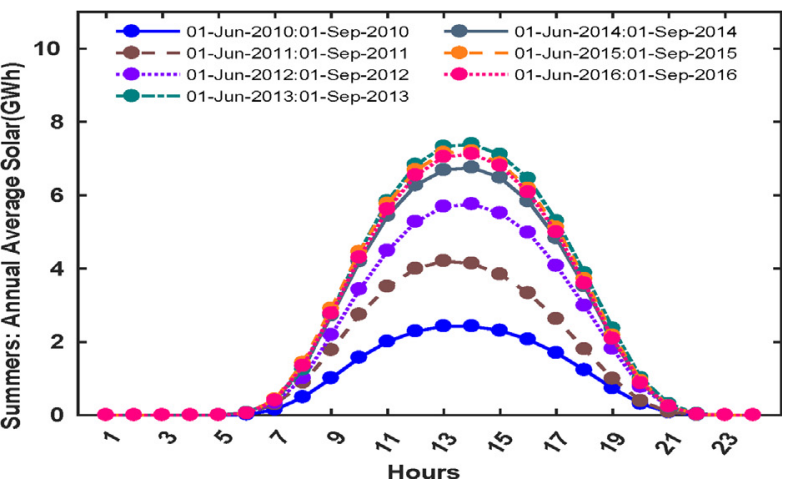

Fig. A.16. Low production of solar and also shorter occurring hours in winters (left), vs. high amount and longer period of solar production during summer (right). 

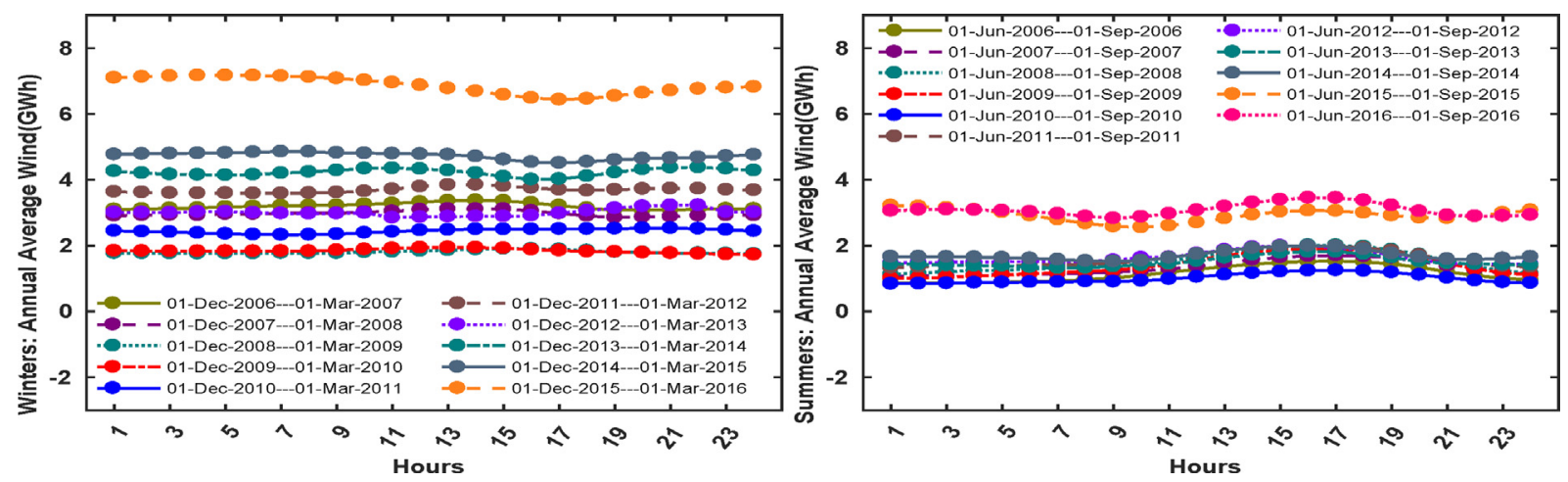

Fig. A.17. Almost smooth and steady harvest of constant wind breathe in winters (left), vs. low production of wind in summer (right).
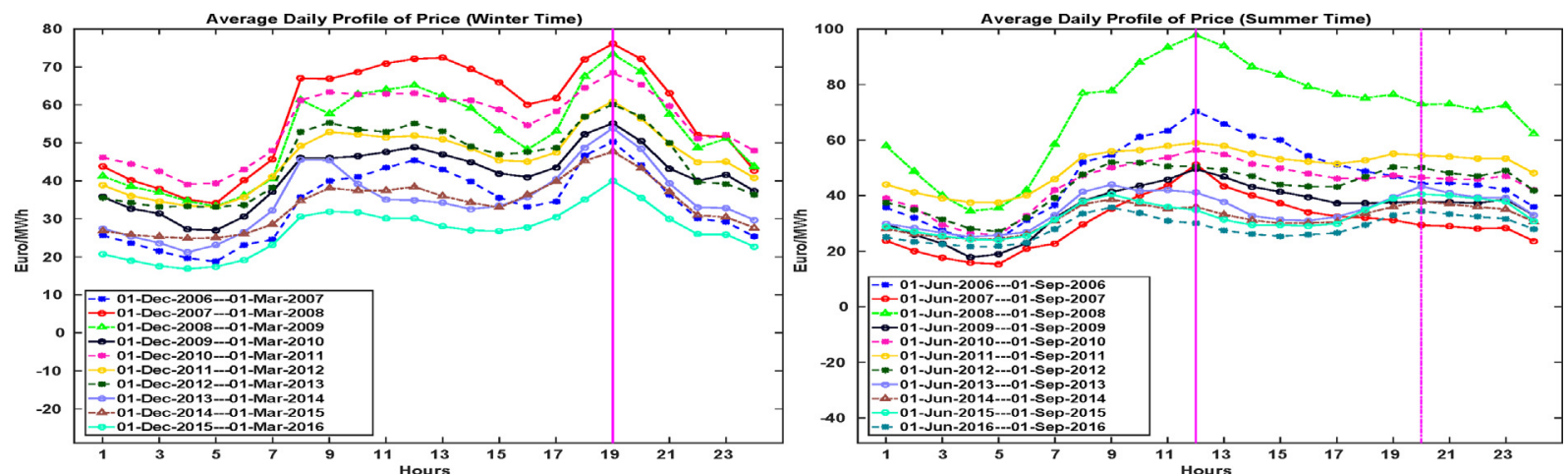

Fig. A.18. The evolution of the seasonal daily average of the price profile during winter time (left) and summer time (right).

Fig. A.18 contrasts the evolution of the daily average of the price profile during winter (December through February) and summer (June through August) season. During the observed period we see that for winter time the peak at $19 \mathrm{~h} 00$ is reduced both in size and sharpness, most likely due to the increase in the wind energy. During the summer period, the morning peak at $12 \mathrm{~h} 00$ disappears completely over the years, in all likelihood again due to the increasing supply of wind and especially solar energy. In other words, the increasing supply of wind and solar energy is not only reducing the electricity price, but it is also changing the daily profile substantially.

Comparing the solar energy feed-in in winters and summers in Fig. A.16 and also considering the evolution of the price profiles in Fig. A.18 allow us to conclude that solar energy, especially in summer, effectively flattens the daytime price profile. Fig. A.18 highlights the evolution of the daily average of the price profiles during winter (December through February) and summer (June through August) season. Every value is the average of the prices for that specific hour, with the average ranging over the specified period. The left panel shows that during winter period the maximum values occur from 18h00-20h00, with peak at $19 \mathrm{~h} 00$. Also, there is a steep increase in the morning (around 7h00). On the other hand, during summer (right panel), the price increase in the morning (5h00-9h00) is considerably flatter. Also the price-spike observed during winter evenings (around 19h00) is completely absent in summers. Both observations underscore the impact of solar on the price.

\section{Appendix A.4. Day-ahead traded quantity (GWh)}

Fig. A.19 displays the evolution of the traded quantity values on the German day-ahead market, in the recent years. Two interesting features are readily apparent. In the left panel the occurrence of a considerable number of outliers (represented as individual points near the upper part of the boxplots) point to unusually high volumes being traded. This highly resembles the wind feed-in profiles in Fig. Appendix A.1. The panel on the right depicts the annual averages of a typical daily profile. Again, the steady increase in the traded volume is evident. However, whereas in the first half of the decade, the traded volume is essentially constant over the course of the day, the latter part of the decade shows an increasingly more prominent bump that mirrors the average supply of solar energy, and could therefore be an indicator of surpluses generated by the renewable energy sources (in particular solar). In 2016, however, we witness a minor reduction in the traded volume, as it may be a direct outcome of warm winter combined with less solar feed-in in that year. 

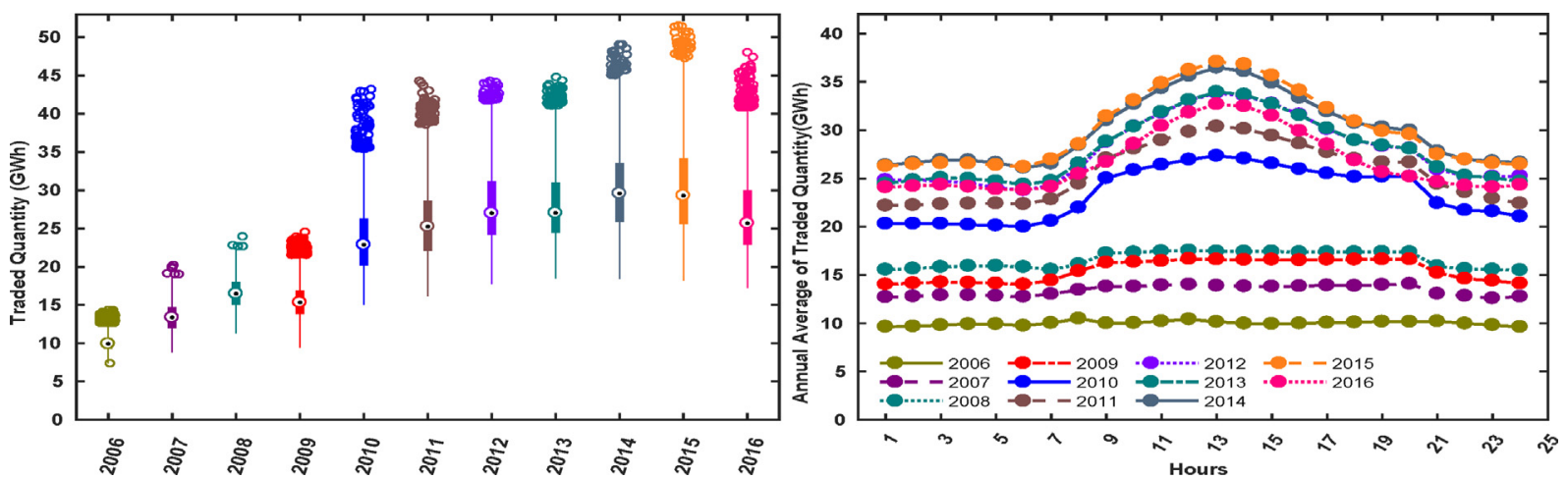

Fig. A.19. Left: Boxplots for the hourly values of traded volumes on the day-ahead market. Right: Daily evolution of the traded volume for each hour slot.

\section{References}

[1] reportFourth "energy transition" monitoring report, https://www.bmwi.de/ BMWi/Redaktion/PDF/V/vierter-monitoring-bericht-energie-der-zukunftenglische-

kurzfassung,property=pdf,bereich $=$ bmwi2012,sprache $=$ de,rwb=true.pdf

[2] Information portal renewable energy, http://www.erneuerbare-energien.de/ EE/Navigation/DE/Service/Erneuerbare_Energien_in_Zahlen/Zeitreihen/ zeitreihen.htm.

[3] A.T. Gullberg, D. Ohlhorst, M. Schreurs, Towards a low carbon energy future-renewable energy cooperation between Germany and Norway, Renew. Energy 68 (2014) 216-222.

[4] D.T. Swift-Hook, Grid-connected intermittent renewables are the last to be stored, Renew. Energy 35 (9) (2010) 1967-1969.

[5] D. Swift-Hook, A. Ter-Gazarian, et al., The value of storage on power systems with intermittent energy sources, Renew. Energy 5 (5) (1994) 1479-1482.

[6] A. Khoshrou, A.B. Dorsman, E.J. Pauwels, Svd-based visualisation and approximation for time series data in smart energy systems, in: 2017 IEEE PES Innovative Smart Grid Technologies Conference Europe (ISGT-europe), 2017, pp. 1-6, https://doi.org/10.1109/ISGTEurope.2017.8260303.

[7] Epexspot, day-ahead auction, https://www.epexspot.com/en/product-info/ auction/germany-austria.

[8] B. Cornélusse, How the European Day-ahead Electricity Market Works, 2014

[9] Epexspot, european power exchange, http://www.epexspot.com/en/market coupling.

[10] M. Angerer, M. Djukow, K. Riedl, S. Gleis, H. Spliethoff, Simulation of cogeneration-combined cycle plant flexibilization by thermochemical energy storage, J. Energy Resour. Technol. 140 (2) (2018), 020909.

[11] I. Simonsen, Volatility of power markets, Phys. Stat. Mech. Appl. 355 (1) (2005) 10-20.

[12] G.H. Golub, C. Reinsch, Singular value decomposition and least squares solutions, Numer. Math. 14 (5) (1970) 403-420.

[13] Financial chaos theory, http://quantonline.co.za/Articles/article_volatility. htm.

[14] R.T. Baillie, C.-F. Chung, M.A. Tieslau, Analysing inflation by the fractionally integrated arfima-garch model, J. Appl. Econom. (1996) 23-40.

[15] M. d. C. Ruiz, A. Guillamón, A. Gabaldón, A new approach to measure volatility in energy markets, Entropy 14 (1) (2012) 74-91.

[16] F.L. Alvarado, R. Rajaraman, Understanding price volatility in electricity markets, in: System Sciences, 2000. Proceedings of the 33rd Annual Hawail International Conference on, IEEE, 2000, p. 5.

[17] E. Denny, A. Tuohy, P. Meibom, A. Keane, D. Flynn, A. Mullane, M. Omalley, The impact of increased interconnection on electricity systems with large penetrations of wind generation: a case study of Ireland and great britain, Energy Pol. 38 (11) (2010) 6946-6954.

[18] K. Gerasimova, et al., Electricity price volatility: its evolution and drivers.
[19] K. Schaber, F. Steinke, T. Hamacher, Transmission grid extensions for the integration of variable renewable energies in europe: who benefits where? Energy Pol. 43 (2012) 123-135.

[20] K. Barnham, K. Knorr, M. Mazzer, Benefits of photovoltaic power in supplying national electricity demand, Energy Pol. 54 (2013) 385-390.

[21] N. Adaduldah, A. Dorsman, G.J. Franx, P. Pottuijt, The influence of renewables on the German day ahead electricity prices, in: Perspectives on Energy Risk, Springer, 2014, pp. 165-182.

[22] I. Daubechies, The wavelet transform, time-frequency localization and signal analysis, IEEE Trans. Inf. Theor. 36 (5) (1990) 961-1005.

[23] Quantifying Volatility Reduction in German Day-ahead Spot Market in the Period 2006 through, 2016. https://arxiv.org/abs/1807.07328v1.

[24] Federal statistical office of germany, https://www.destatis.de/EN/ FactsFigures/EconomicSectors/Energy/Production/Tables/ GrossElectricityProduction.html.

[25] A. Zipp, The marketability of variable renewable energy in liberalized electricity markets-an empirical analysis, Renew. Energy 113 (2017) 1111-1121.

[26] J. Cludius, H. Hermann, F.C. Matthes, V. Graichen, The merit order effect of wind and photovoltaic electricity generation in Germany 2008-2016: estimation and distributional implications, Eneroy Econ. 44 (2014) 302-313.

[27] K. Würzburg, X. Labandeira, P. Linares, Renewable generation and electricity prices: taking stock and new evidence for Germany and Austria, Energy Econ. 40 (2013) S159-S171.

[28] T. Brijs, K. De Vos, C. De Jonghe, R. Belmans, Statistical analysis of negative prices in european balancing markets, Renew. Energy 80 (2015) 53-60.

[29] E. Denny, A. O'Mahoney, E. Lannoye, Modelling the impact of wind generation on electricity market prices in Ireland: an econometric versus unit commitment approach, Renew. Energy 104 (2017) 109-119.

[30] Electricity interconnectors, http://www.ofgem.gov.uk/electricity $\Omega /$ transmission-networks/electricity-inetrconnectors.

[31] Greenlink interconnector, https://www greenlinkinterconnectoreu/.

[32] A.B. Dorsman, A. Nentjes, P. Polak, Geostrategy of the European Union in energy, in: Energy Economy, Finance and Geostrategy, Springer, 2018, pp. 199-220.

[33] E. Vasileva, S. Viljainen, P. Sulamaa, D. Kuleshov, Res support in Russia: impact on capacity and electricity market prices, Renew. Energy 76 (2015) 82-90.

[34] E. Martinot, Renewable energy in Russia: markets, development and technology transfer, Renew. Sustain. Energy Rev. 3 (1) (1999) 49-75.

[35] H. Karunathilake, K. Hewage, W. Mérida, R. Sadiq, Renewable energy selection for net-zero energy communities: life cycle based decision making under uncertainty, Renew. Energy 130 (2019) 558-573.

[36] J. Chaves-Ávila, C. Fernandes, The Spanish intraday market design: a successful solution to balance renewable generation? Renew. Energy 74 (2015) 422-432.

[37] Duurzaam, http://www.duurzaambedrijfsleven.nl/industrie/15265/grootstebatterij-ter-wereld-wordt-game-changer-voor-energiesysteem. 